\title{
ОПТИМИЗАЦИЯ УСЛОВИЙ, УЛУЧШАЮЩИХ ПРОРАСТАНИЕ СЕМЯН КОК-САГЫЗА Taraxacum kok-saghyz Rodin*
}

\author{
G. SHEN ${ }^{1,2}$, F. CHEN 2 , W. WANG1 1 F. ZHENG ${ }^{2}$, D. WEI ${ }^{2}$, L. LI², \\ Н.Г. КОНЬКОВА 3
}

\begin{abstract}
В настоящее время кок-сагыз считается наиболее перспективным источником натурального каучука, и во многих странах для разработки технологий производства каучука на основе использования этого вида растений привлекает значительные инвестиции. Обеспечение высокого процента быстрого и равномерного прорастания важно для выращивания кок-сагыза. В представленной работе мы получили результаты, существенно расширяющие представления о температуре как факторе, влияющем на характеристики всхожести семян у T. kok-saghyz, что важно для практики размножения этого каучуконоса. Цель нашего исследования состояла в том, чтобы предложить практический и простой метод улучшения прорастания семян кок-сагыза (Taraxacum kok-saghyz Rodin) - русского одуванчика. Схему трехфакторного дисперсионного анализа L9 $\left(3^{4}\right)$ использовали для оптимизации трех факторов - концентрации раствора $\mathrm{KMnO}_{4}(0,07 \%, 0,1 \%$ и $0,2 \%)$, времени замачивания $\left(1,2\right.$ и 4 ч) и температуры прорастания $\left(4 / 17,17\right.$ и $\left.23{ }^{\circ} \mathrm{C}\right)$. Оценивались показатели всхожести, включая процент всхожести, $\mathrm{T}_{50}$ (время, необходимое для прорастания $50 \%$ семян), индекс всхожести и энергия прорастания. Оптимальными для прорастания оказались 2 ч замачивания в $0,07 \%$ растворе $\mathrm{KMnO}_{4}$ и проращивание при температуре $23{ }^{\circ} \mathrm{C}$. В оптимальных условиях доля проросших семян составила $71 \%$, величина $\mathrm{T}_{50}-11$ сут, а показатели всхожести и индекс прорастания составили соответственно 7,22 и 14,40. Кроме того, мы обнаружили, что, помимо наличия влаги, основным фактором, влияющим на прорастание семян T. kok-saghyz, была температура. Состав и концентрация раствора, а также время замачивания либо не влияли на всхожесть семян, либо изменяли ее незначительно.
\end{abstract}

Ключевые слова: всхожесть, равномерность прорастания, $\mathrm{KMnO}_{4}$, Taraxacum koksaghyz Rodin, кок-сагыз, русский одуванчик.

Taraxacum kok-saghyz Rodin (русский одуванчик) - травянистое многолетнее растение. Корень содержит (по массовой доле) от 2,89\% до $27,89 \%$ натурального каучука с молекулярной массой $2180(1,2)$ и 2540 \% инулина (3). Этот вид потенциально может быть использован в качестве модельной системы для выявления механизма синтеза каучука (4). В настоящее время кок-сагыз считается наиболее перспективным источником натурального каучука, и во многих странах для разработки технологий производства каучука на основе использования этого вида растений привлекает значительные инвестиции $(1,2,5)$.

Обеспечение высокого процента быстрого и равномерного прорастания важно для выращивания кок-сагыза (6). Семена как-сагыза обладают довольно длинным послеуборочным периодом покоя. Для достижения высокого процента быстрого и равномерного прорастания необходимо обеспечить эффективный выход семян из этого состояния. В качестве факторов активации изучали стратификацию, предварительное охлаждение (6), замачивание и химические воздействия, кроме того, анализировали влияние температуры, влажности и ряда других факторов на всхожесть (6). При применении этих методов нарушения покоя было установлено, что требуется как минимум 24-часовая предварительная обработка, что замедляет процедуру получения проростков. Кроме того, при повышенной влажности семена могут повреждаться плесневыми грибами.

В некоторых работах было показано, что $\mathrm{KMnO}_{4}$ не только обеспе-

\footnotetext{
* Работа выполнена в рамках государственного задания ВИР по теме № 0662-2019-0001 и поддержана Академией наук провинции Хэйлунцзян (грант № 2014ST06), а также проектом 2014AE4AE053 Технологического университета города Харбин.
} 
чивает поверхностную стерилизацию семян, но и инициирует их выход из состояния покоя (7-9). Однако влияние раствора $\mathrm{KMnO}_{4}$ на прорастание семян у $T$. kok-saghyz остается невыясненным. Более того, предыдущие исследования в основном были посвящены влиянию обработок на процент всхожести семян T. kok-saghyz, но при этом игнорировались другие важные для прорастания и последующего роста рассады показатели равномерность и индекс прорастания, энергия всхожести.

В представленной работе мы получили результаты, существенно расширяющие представления о температуре как факторе, влияющем на характеристики всхожести семян у $T$. kok-saghyz, что важно для практического применения методов размножения этого каучуконоса.

Цель работы - оптимизировать условия прорастания семян коксагыза с использованием раствора $\mathrm{KMnO}_{4}$, а также изучить влияние температуры, концентрации раствора и времени замачивания на прорастание.

Методика. Семена кок-сагыза (Taraxacum kok-saghyz Rodin) получили из коллекции ВИР (Всероссийский НИИ генетических ресурсов растений, образец к-445). Растения размножали и выращивали на экспериментальной базе (4534'59,9" с.ш., 126 34'18,8" в.д., г. Харбин, Китай) в 2014 году. Плоды сушили на воздухе в течение 2 нед, затем вручную очищали для извлечения семян. Для очистки семян последовательно использовали два сита с диаметром отверстий 0,42 и 0,83 мм. Семена хранили в течение 5 мес при комнатной температуре.

Семена предварительно тестировали на жизнеспособность, замачивая в $1 \%$ растворе хлорида трифенилтетразолия (ТТС) в течение 30 мин (10). После замачивания в растворе $\mathrm{KMnO}_{4}$ или в воде семена равномерно раскладывали на два слоя увлажненной фильтровальной бумаги и помещали в чашки Петри $(9,0 \times 2,5$ см) для прорастания. В чашки Петри регулярно добавляли воду, чтобы семена оставались влажными.

На основании предыдущих исследований были выбраны три фактора (концентрация раствора, время замачивания и температура), каждый из которых анализировали в трех вариантах значений $-0\left(\mathrm{~L}_{0}\right), 1\left(\mathrm{~L}_{1}\right)$ и 2 $\left(\mathrm{L}_{2}\right)$ с использованием схемы трехфакторного дисперсионного анализа [L $\mathrm{L}_{9}$ $\left.\left(3^{4}\right)\right]$, состоящего из девяти комбинаций признаков. Каждый вариант обработки анализировали в 3 повторностях (три чашки Петри с 50 семенами в каждой). Уровни (L) для каждого фактора: концентрация $\mathrm{KMnO}_{4}$ (массовая доля) $\mathrm{L}_{0}=0,07 \%, \mathrm{~L}_{1}=0,1 \% ; \mathrm{L}_{2}=0,2 \%$; время замачивания в $\mathrm{KMnO}_{4} \mathrm{~L}_{0}=1$ ч, $\mathrm{L}_{1}=2$ ч, $\mathrm{L}_{2}=4$ ч; температура проращивания после замачивания $\mathrm{L}_{0}=23{ }^{\circ} \mathrm{C}, \mathrm{L}_{1}=17{ }^{\circ} \mathrm{C}, \mathrm{L} 2=17{ }^{\circ} \mathrm{C} 16$ ч $+4{ }^{\circ} \mathrm{C} 8$ ч.

Для выявления влияния пониженной температуры на прорастание семян провели две низкотемпературные обработки $\left(4^{\circ} \mathrm{C}\right)$ в разные сроки. Для оценки воздействия нитрата калия $\left(\mathrm{KNO}_{3}\right)$ на физиологическое созревание семян их обрабатывали $3 \%$ раствором этой соли.

В качестве контроля использовали дистиллированную воду, каждую процедуру повторяли трижды.

Всхожесть семян оценивали в течение 20 сут после помещения семян в чашки Петри для первого эксперимента с целью определения уровней различных факторов для улучшения всхожести T. kok-saghyz. Для экспериментов, направленных на подтверждение улучшенной обработки, всхожесть семян оценивали в течение 14 сут. Семена считали проросшими при длине корешка 1 мм и более. Прорастание семян оценивали по четырем параметрам, характеризующим время, скорость, однородность и синхронность прорастания (11), которые рассчитывали по следующим формулам: всхожесть $=($ общее число проросших семян/общее число семян $) \times 100, \%$; 
индекс прорастания $=\sum$ (семена, проросшие за 1 сут/время проращивания, сут); энергия прорастания $=$ (индекс прорастания $\times$ длина корешка, мм); равномерность прорастания $\mathrm{T}_{50}-$ время прорастания $50 \%$ семян.

Для обработки статистических данных использовали программное обеспечение SPSS v.19.0 («IBM», США) с последующим применением многорангового теста Дункана.

Результаты. Оцененные нами показатели прорастания семян достаточны для комплексной оценки происходящих процессов роста и накопления биомассы. Для трех значений каждого из проанализированных факторов в итоге формировали схему трехфакторного дисперсионного анализа $\mathrm{L}_{9}\left(3^{4}\right)$ (табл. 1).

\section{1. Схема трехфакторного дисперсионного анализа $L_{9}\left(3^{4}\right)$ по оптимизации усло- вий проращивания семян кок-сагыза Taraxacum kok-saghyz Rodin}

\begin{tabular}{c|c|c|c|c}
\hline \multirow{2}{*}{$\begin{array}{c}\text { Вариант } \\
\text { обработки }\end{array}$} & \multicolumn{3}{|c}{ Фактор } \\
\cline { 2 - 5 } & раствор $\mathrm{KMnO}_{4}(\%)$ & время, ч & температура, ${ }^{\circ} \mathrm{C}$ & номер повторности \\
\hline 1 & $1(0,07 \%)$ & $3(4)$ & $3(23)$ & 1 \\
2 & $2(0,1 \%)$ & $2(2)$ & $3(23)$ & 2 \\
3 & $3(0,2 \%)$ & $1(1)$ & $3(23)$ & 3 \\
4 & $3(0,2 \%)$ & $2(2)$ & $1(4-17)$ & 1 \\
5 & $1(0,07 \%)$ & $1(1)$ & $1(4-17)$ & 2 \\
6 & $1(0,07 \%)$ & $2(2)$ & $2(17)$ & 2 \\
7 & $2(0,1 \%)$ & $1(1)$ & $2(17)$ & 3 \\
8 & $2(0,1 \%)$ & $3(4)$ & $1(4-17)$ & 1 \\
9 & $3(0,2 \%)$ & $3(4)$ & $2(17)$ & \\
\hline
\end{tabular}

Тестирование показало, что 81,57 \% семян, использованных в настоящем исследовании, были жизнеспособными.

Влияние трех изученных факторов на всхожесть семян T. kok-saghyz. Концентрация раствора $\mathrm{KMnO}_{4}$ значительно повлияла на энергию прорастания семян $T$. kok-saghyz (p < 0,05), но не проявила значимого эффекта при оценке всхожести, однородности прорастания или индекса всхожести (p > 0,05). Время замачивания практически не влияло ни на один из четырех показателей прорастания семян $(\mathrm{p}>0,05)$, тогда как температура влияла на все индексы прорастания ( $<0,05)$, и в наибольшей степени - на энергию прорастания $(\mathrm{p}<0,01)$ (табл. 2).

2. Влияние трех факторов на параметры прорастания семян у кок-сагыза $\mathbf{T a}$ raxacum kok-saghyz Rodin

\begin{tabular}{ll|r|r|r|r}
\hline \multicolumn{1}{c|}{ Фактор } & \multicolumn{1}{c|}{ Зависимая переменная } & df & \multicolumn{1}{c|}{$\mathrm{ms}$} & \multicolumn{1}{c}{$F$} & Sig. \\
\hline Концентрация КМnО 4 & Прорастание, \% & 2 & 34,111 & 1,415 & 0,414 \\
& Равномерность прорастания, сут & 2 & 4,370 & 1,489 & 0,402 \\
& Индекс прорастания & 2 & 3,356 & 5,446 & 0,155 \\
Время & Энергия прорастания & 2 & 10,414 & 36,596 & 0,027 \\
& Прорастание, \% & 2 & 15,444 & 0,641 & 0,610 \\
& Равномерность прорастания, сут & 2 & 0,961 & 0,328 & 0,753 \\
Температура & Индекс прорастания & 2 & 0,200 & 0,325 & 0,755 \\
& Энергия прорастания & 2 & 2,487 & 8,738 & 0,103 \\
& Прорастание, \% & 2 & 707,111 & 29,327 & 0,033 \\
Ошибка & Равномерность прорастания, сут & 2 & 230,633 & 78,583 & 0,013 \\
& Индекс прорастания & 2 & 14,339 & 23,266 & 0,041 \\
& Энергия прорастания & 2 & 38,644 & 135,793 & 0,007 \\
& Прорастание, \% & 2 & 24,111 & & \\
& Равномерность прорастания, сут & 2 & 2,935 & & \\
& Индекс прорастания & 2 & 0,616 & & \\
& Энергия прорастания & 2 & 0,285 & &
\end{tabular}

Пр и м еч а н и е. $\mathrm{df}-$ степени свободы, $\mathrm{ms}-$ средний квадрат отклонений, $F-$ критерий Фишера, Sig. - доверительная вероятность.

Установление режима обработки, оптимального для прорастания семян. Для всхожести предпочтительнее более высокие значения. Однако мы обнаружили, что с увеличением концентрации раствора $\mathrm{KMnO}_{4}$ процент проросших семян снижается. Кроме того, ни увеличение, 
ни сокращение периода замачивания в растворе $\mathrm{KMnO}_{4}$ не улучшало этот показатель. Оптимальной продолжительностью замачивания следует считать 2 ч. Хотя обработка $17{ }^{\circ} \mathrm{C}+4{ }^{\circ} \mathrm{C}$ приводила к повышению процента прорастания по сравнению с показателем в варианте $4{ }^{\circ} \mathrm{C}$, самый высокий показатель зафиксировали при $23^{\circ} \mathrm{C}$. В результате в качестве оптимальных условий для прорастания семян кок-сагыза приняты следующие: 1,0\% раствор $\mathrm{KMnO}_{4}$, замачивание в течение 2 ч, проращивание при $23{ }^{\circ} \mathrm{C}$ (рис. 1).
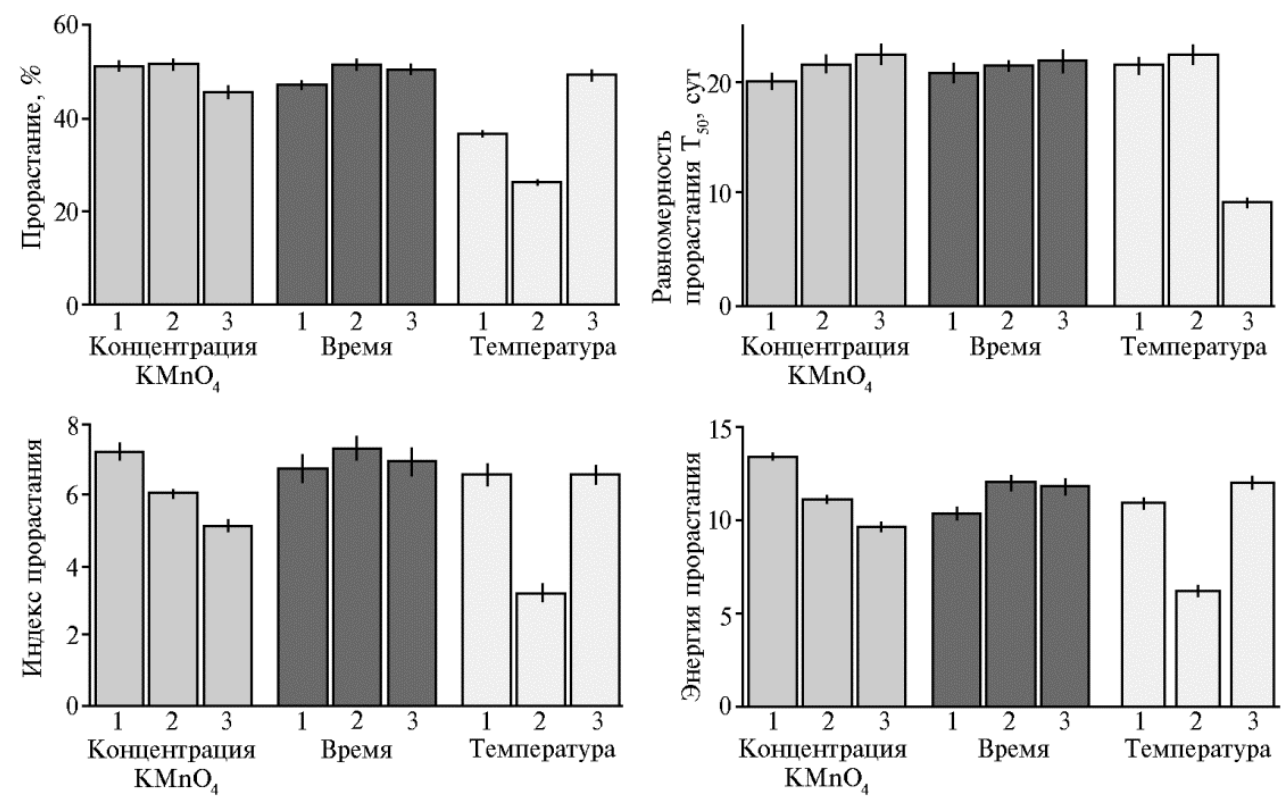

Рис. 1. Показатели прорастания семян у кок-сагыза Taraxacum kok-saghyz Rodin при изменении воздействующих факторов: 1, 2, 3 - градации факторов (описание схемы опыта см. в разделе «Методика»).

По показателю $\mathrm{T}_{50}$ предпочтительнее более низкие значения. При увеличении как концентрации $\mathrm{KMnO}_{4}$, так и времени замачивания равномерность прорастания повышалась, а результат проращивания при $23{ }^{\circ} \mathrm{C}$ был лучше, чем в остальных вариантах $\left(17^{\circ} \mathrm{C}+4{ }^{\circ} \mathrm{C}\right.$ и $\left.17^{\circ} \mathrm{C}\right)$. Поэтому оптимальным для равномерного прорастания оказалось замачивание в $0,07 \%$ растворе $\mathrm{KMnO}_{4}$ в течение 1 ч и проращивание при $23{ }^{\circ} \mathrm{C}$ (см. рис. 1). Для индекса прорастания также более предпочтительны высокие значения. С повышением концентрации $\mathrm{KMnO}_{4}$ индекс прорастания уменьшался. Оптимальными условиями оказались замачивание в течение 2 ч и температура прорастания $23^{\circ} \mathrm{C}$. Таким образом, самый высоки индекс прорастания отмечали при использовании $0,07 \%$ раствора $\mathrm{KMnO}_{4}$, время замачивания 2 ч и температура прорастания $23{ }^{\circ} \mathrm{C}$ (см. рис. 1). Те же условия, что и для индекса прорастания, оказались оптимальными для обеспечения высокой энергии прорастания $\left(0,07 \%\right.$ раствор $\mathrm{KMnO}_{4}$, время замачивания 2 ч и температура прорастания $23{ }^{\circ} \mathrm{C}$ ) (см. рис. 1$)$.

Таким образом, при концентрации $\mathrm{KMnO}_{4} 0,07 \%$ и температуре прорастания $23{ }^{\circ} \mathrm{C}$ все индексы, кроме времени прорастания, были самыми высокими, а замачивание в течение 2 ч обеспечивало наибольшие значения всех показателей прорастания без исключения. Учитывая, что время замачивания в растворе $\mathrm{KMnO}_{4}$ не оказывало существенного влияния ни на один из показателей прорастания семян у кок-сагыза (см. табл. 2), можно считать время замачивания 2 ч оптимальным. То есть в этих тестах мы пришли к выводу, что оптимальные условия по большинству показателей 
прорастания семян T. kok-saghyz следующие: замачивание в 0,07 \% (массовая доля) растворе $\mathrm{KMnO}_{4}$ в течение 2 ч с проращиванием при $23{ }^{\circ} \mathrm{C}$.

Оценка режима проращивания семян кок-сагыза. Определив оптимальные значения выбранных факторов, для их проверки мы рассмотрели эффекты пяти вариантов обработок (табл. 3).

3. Варианты обработки, использованные для проверки предложенной схемы проращивания семян кок-сагыза Taraxacum kok-saghyz Rodin

\begin{tabular}{c|l|c|c|c}
\hline $\begin{array}{l}\text { Вариант } \\
\text { обработки }\end{array}$ & \multicolumn{1}{|c|}{ Раствор } & Концентрация, \% & $\begin{array}{c}\text { Время зама- } \\
\text { чивания, ч }\end{array}$ & Температура, ${ }^{\circ} \mathrm{C}$ \\
\hline \multicolumn{2}{c}{$\mathrm{KMnO}_{4}$} & 0,07 & 2 & $23{ }^{\circ} \mathrm{C}$ \\
2 & $\mathrm{KMnO}_{4}$ & 0,07 & 2 & $4{ }^{\circ} \mathrm{C}$ в течение 1 нед, далее $23{ }^{\circ} \mathrm{C}$ \\
3 & $\mathrm{KMnO}_{4}$ & 0,07 & 2 & $4{ }^{\circ} \mathrm{C}$ в течение 2 нед, далее $23^{\circ} \mathrm{C}$ \\
4 & $\mathrm{KNO}_{3}$ & 3,00 & 24 & $23^{\circ} \mathrm{C}$ \\
5 & Дистиллированная вода & & 2 & $23^{\circ} \mathrm{C}$ \\
\hline
\end{tabular}

В этом эксперименте именно определенные ранее оптимальные условия обработки (вариант 1) дали самый высокий процент прорастания (71 \%) (рис. 2). J. Levitt и Р. Наmm (12) предположили, что определенные концентрации раствора $\mathrm{KNO}_{3}$ могут повысить процент прорастания и другие его показатели, способствуя физиологическому созреванию семян. Поэтому мы также применили обработку $3 \%$ раствором $\mathrm{KNO}_{3}$. Хотя этот раствор увеличивал процент прорастания семян у T. kok-saghyz, повышение было достоверно ниже, чем полученное с использованием идентифицированной оптимальной обработки $(\mathrm{p}<0,05)$. Некоторые авторы $(13,14)$ предполагали, что низкая температура (обычно 0-5 ${ }^{\circ} \mathrm{C}$ ) может повысить равномерность прорастания семян. В нашем опыте 1 нед воздействия температурой $4{ }^{\circ} \mathrm{C}$ повышала процент прорастания по сравнению с контрольной обработкой, но не достоверно (p > 0,05), а выдерживание при $4{ }^{\circ} \mathrm{C}$ в течение 2 нед не увеличивало процент прорастания (см. рис. 2).

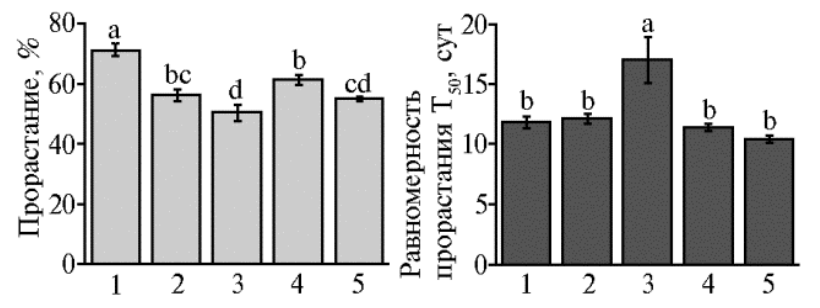

Рис. Результаты оценки выбранных условий проращивания семян кок-сагыза Taraxacum kok-saghyz Rodin при сравнении с другими приемами обработки: $1,2,3,4,5$ варианты обработки (см. табл. 3).

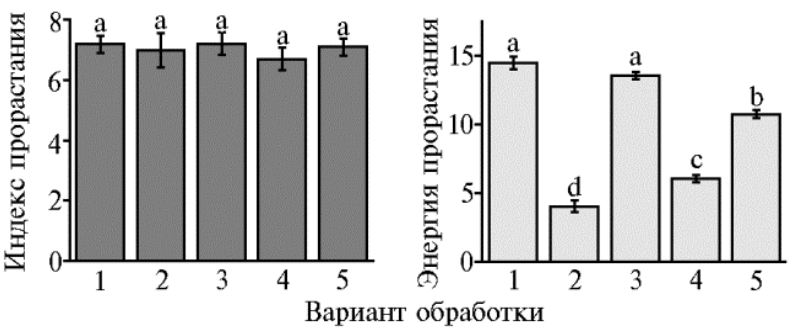

При воздействии температурой $4{ }^{\circ} \mathrm{C}$ в течение 2 нед равномерность прорастания значительно снижалась по сравнению с другими вариантами (величина $\mathrm{T}_{50}$ увеличивалась до 17 сут). По другим вариантам существенных различий мы не отмечали.

Все четыре варианта обработки не оказали значимого влияния на индекс прорастания в сравнении с контролем (см. рис. 2). Учитывая, что во всех пяти вариантах семена прорастали при одной и той же температуре, мы можем предположить, что температура проращивания - единственный фактор, влияющий на индекс прорастания семян у T. kok-saghyz (независимо от вариантов их предварительной обработки, включая состав и концентрацию раствора, используемого для замачивания семян, и предварительное выдерживание при низкой температуре). 
Самый высокий показатель энергии прорастания - 14,40 получили при использовании оптимизированных условий обработки. Выдерживание при $4{ }^{\circ} \mathrm{C}$ в течение 1 нед привело к наибольшему снижению энергии прорастания. Напротив, через 2 нед воздействия $4{ }^{\circ} \mathrm{C}$ индекс энергии прорастания был выше величины, сопоставимой с таковой при применении оптимизированных условий $(\alpha=0,05)$. Обработка $\mathrm{KNO}_{3}$ значительно снизила энергию прорастания семян по сравнению с контролем.

В выполненном исследовании мы показали, что температура значительно влияет на все показатели прорастания семян кок-сагыза. Таким образом, можно констатировать, что, помимо влаги, температуру следует считать основным фактором, влияющим на прорастание семян $T$. koksaghyz. Состав и концентрация раствора, а также время замачивания практически не влияли на прорастание семян T. kok-saghyz. Этот вывод в некоторой степени согласуется с выводами J. Levitt и P. Hamm (12). Поэтому если семена T. kok-saghyz содержать при оптимальной влажности и проращивать при подходящей температуре $\left(23{ }^{\circ} \mathrm{C}\right)$, то в большинстве случаев это обеспечит желаемые результаты.

Как уже отмечалось, мы определили, что оптимальные условия для прорастания семян $T$. kok-saghyz - замачивание в $0,7 \%$ раствор $\mathrm{KMnO}_{4}$ в течение 2 ч и проращивание при $23{ }^{\circ} \mathrm{C}$, что впоследствии подтвердил эксперимент по проверке. В этих условиях прорастание достигало $71 \%$, равномерность прорастания составляла приблизительно 11 сут, а индекс прорастания и энергия прорастания составляли соответственно 7,22 и 14,40. Процент прорастания, полученный в нашем исследовании, был ниже, чем в предыдущих $(6,12)$, как и равномерность прорастания. Эти различия, вероятно, могут объясняться неодинаковым качеством семян. Однако, учитывая, что 81,57 \% семян, которые мы использовали, были жизнеспособными, мы считаем, что наши результаты верны. Кроме того, в проверочном эксперименте мы использовали раствор $\mathrm{KNO}_{3}$ для вывода семян из состояния покоя (вариант 4), как это было предложено J. Levitt и P. Hamm (12), но не получили более высокий процент всхожести, как описано ими. Таким образом, единственная правдоподобная причина, объясняющая эти контрастные результаты, - качество семян, в частности степень их зрелости (появление пустых и незрелых семян). Следовательно, для дополнительной проверки предложенного нами метода требуются семена лучшего качества. Семена, использованные в настоящем исследовании, были однолетними. Необходимы дальнейшие исследования, чтобы определить, как семена старше 2 лет отреагируют на эти экспериментальные условия и насколько применимы оптимизированные условия.

Согласно E.H. Roberts (15), температура влияет на три физиологических процесса в семенах: во-первых, температура вместе с влажностью определяет скорость ухудшения состояния семян, во-вторых, влияет на скорость выхода из состояния покоя у сухих семян и характер изменения состояния покоя у влажных семян, в-третьих, в семенах, не находящихся в состоянии покоя, температура определяет скорость прорастания. Поэтому, прежде чем обсуждать влияние температуры на всхожесть семян, важно знать, являются ли семена T. kok-saghyz покоящимися. Предыдущее исследование показало, что семена $T$. kok-saghyz находятся в состоянии покоя в период после созревания. Под покоем семян понимается состояние, при котором жизнеспособные семена не прорастают, когда им предоставляются условия, обычно благоприятные для прорастания, такие как достаточная влажность и соответствующая температура и освещенность (16). Наш эксперимент показал, что в варианте 1 прорастание со- 
ставляло $71 \%$, что было значительно выше, чем в контроле (54 \%) при тех же условиях. Следовательно, примерно $17 \%$ семян были в состоянии покоя, и для прорастания требовалась их стимуляция с помощью $\mathrm{KMnO}_{4}$. Однако большинство однолетних семян T. kok-saghyz не находятся в состоянии покоя. Поэтому скорость прорастания семян T. kok-saghyz определяется температурой.

Широко признано, что предварительная обработка окислителями, такими как $\mathrm{KMnO}_{4}$ и $\mathrm{H}_{2} \mathrm{O}_{2}$, нарушает состояние покоя семян (17). В настоящем исследовании мы наблюдали, что семена, обработанные раствором $\mathrm{KMnO}_{4}$, были менее поражены плесневыми грибами (примерно $15 \%$ от общего числа), чем необработанные. Поэтому мы считаем, что $\mathrm{KMnO}_{4}$ оказывает на семена T. kok-saghyz два типа воздействия. Во-первых, $\mathrm{KMnO}_{4}$ улучшает всхожесть, так как выводит семена из состояния покоя, удаляя семенную оболочку и обеспечивая кислородом и марганцем для облегчения прорастания. Во-вторых, $\mathrm{KMnO}_{4}$ обладает стерилизующим эффектом и тем самым предотвращает образование плесени. Поскольку мы обнаружили, что большинство заплесневелых семян были пустыми, мы считаем, что $\mathrm{KMnO}_{4}$ увеличил всхожесть семян $T$. kok-saghyz, способствуя, главным образом, их переходу в активное состояние. Однако концентрация $\mathrm{KMnO}_{4}$ должна быть ограничена (не более $0,1 \%$, оптимально 0,07 \%), в противном случае жизнеспособность проросших семян может снизиться.

Мы полагаем, что $23{ }^{\circ} \mathrm{C}$ - оптимальная температура для прорастания семян T. kok-saghyz. При $4{ }^{\circ} \mathrm{C}$ в нашем опыте они не прорастали, что, однако, не согласуется с данными J. Levitt и P. Hamm (12), которые показали, что семена кок-сагыза могут прорастать при такой температуре. Мы замачивали семена в растворе $\mathrm{KMnO}_{4}$ только за 4 ч до проращивания при $4{ }^{\circ} \mathrm{C}$, то есть в течение гораздо более короткого периода, чем тот, который использовали в цитируемой работе (12). Возможно, семенам T. kok-saghyz требуется более длительное замачивание в растворе $\mathrm{KMnO}_{4}$ для поглощения количества воды, необходимого для прорастания при $4{ }^{\circ} \mathrm{C}$.

В настоящем исследовании вариант комбинированной обработки при $17{ }^{\circ} \mathrm{C}+4{ }^{\circ} \mathrm{C}$ показал превосходные результаты по сравнению с обработкой при $17{ }^{\circ} \mathrm{C}$ по всем показателям прорастания. Это согласуется с выводами работ $(18,19)$, в которых ранее показали, что в условиях изменяющейся температуры семена могут прорасти быстрее, чем можно прогнозировать для одного температурного режима. Мы предполагаем, что обработка с чередованием температур $\left(4 / 23^{\circ} \mathrm{C}\right)$ способна улучшить прорастание семян по сравнению с эффектом одной температуры $\left(23^{\circ} \mathrm{C}\right)$. Это составит предмет наших дальнейших исследований.

Итак, полученные нами результаты показывают, что, помимо влаги, температура служит основным фактором, влияющим на прорастание семян кок-сагыза Taraxacum kok-saghyz. Состав и концентрация растворов и время замачивания практически не влияют на прорастание семян. Для семян T. kok-saghyz, которые хранились в течение 1 года, оптимальные условия, определенные в нашем эксперименте, включают замачивание в $0,7 \%$ растворе $\mathrm{KMnO}_{4}$ в течение 2 ч перед проращиванием при $23{ }^{\circ} \mathrm{C}$. Однако эффективность этого режима должна быть также подтверждена в полевых испытаниях. Кроме того, поскольку большинство однолетних семян T. kok-saghyz, использованных в настоящей работе, не находились в состоянии покоя, предложенные оптимальные режимы следует также проанализировать с использованием более старых семян, что составит предмет наших 


\section{Л ИТЕ РАТ УРА}

1. Mooibroek H., Cornish K. Alternative sources of natural rubber. Appl. Microbiol. Biotechnol., 2000, 53(4): 355-365 (doi: 10.1007/s002530051627).

2. Van Beilen J.B., Poirier Y. Establishment of new crops for the production of natural rubber. Trends in Biotechnology, 2007, 25(11): 522-529 (doi: 10.1016/j.tibtech.2007.08.009).

3. Polhamus L.G. Rubber: botany, production and utilization. Interscience Publ., New York, 1962.

4. Schmidt T., Lenders M., Hillebrand A., van Deenen N., Munt O., Reichelt R., Eisenreich W., Fischer R., Prufer D., Schulze Gronover C. Characterization of rubber particles and rubber chain elongation in Taraxacum koksaghyz. BMC Biochemistry, 2010, 11: 11 (doi: 10.1186/14712091-11-11).

5. Venkatachalam P., Geetha N., Sangeetha P., Thulaseedharan A. Natural rubber producing plants: an overview. African Journal of Biotechnology, 2013, 12(12): 1297-1310 (doi: 10.5897/AJBX12.016).

6. Whaley W.G., Bowen J.S. Russian dandelion (kok-saghyz): an emergency source of natural rubber. US Department of Agriculture, Washington, D.C., 1947.

7. Meng H., Wang X., Tong S., Lv X., Zhang W., Huo L., Cao X., Meng X. Effects of pretreatments on seeds of Leucaena leucocephala and Phragmites australis. Chinese Journal of Ecology, 2013, 19: 6142-6146.

8. Wang H., Chen Z., Zhang Y., Yang Y., Du S., Guo T. Influence of soaking time and agents on seed germination of Poa pratensis. Pratacultural Science (China), 2014, 11: 2095-2104.

9. Yang, Y., Wang, H., Yang, X., Cheng T. Effect of sterilization on seed germination of Festuca arundinacea. Acta Agrestia Sinica, 2014, 02: 380-385.

10. International Seed Testing Association. International Rules for Seed Testing. Seed Sci. \& Technol., 1999, 27(Suppl.): 35.

11. Ranal M.A., de Santana D.G. How and why to measure the germination process? Brazilian Journal of Botany, 2006, 29(1): 1-11 (doi: 10.1590/S0100-84042006000100002).

12. Levitt J., Hamm P. A method of increasing the rate of seed germination of Taraxacum koksaghyz. Plant Physiology, 1943, 18(2): 288-293.

13. Singh S., Singh P., Sanders D.C., Wehner T.C. Germination of watermelon seeds at low temperature. Cucurbit Genetics Cooperative, 2001, 24: 59-64.

14. Yari L., Zareyan A., Sheidaie S., Khazaei F. Influence of high and low temperature treatments on seed germination and seedling vigor of rice (Oryza sativa L.). World Applied Sciences Journal, 2012, 16(7): 1015-1018.

15. Roberts E.H. Temperature and seed germination. Symposia of the Society for Experimental Biology, 1988, 42: 109-132.

16. Schmidt L. Guide to handling of tropical and subtropical forest seeds. Danida Forest Centre, Denmark, 2000.

17. Jann R.C., Amen R.D. What is germination? In: The physiology and biochemistry of seed dormancy and germination /A.A. Khan (ed.). North Holland Publishing Co., Amsterdam, 1977: 7-28.

18. Hegarty T.W. Temperature relations of germination in the field. In: Seed ecology /W. Heydecker (ed.). Butterworths, London, 1973: 411-432.

19. Gavrilova V.A., Konkova N.G., Kutuzova S.N., Gavrilenko T.A., Pendinen G.I., Dunaeva S.E., Podolnaya L.P., Petrosyan I., Fan Y., Zeng X., Zhang J., Shen G. Kok-saghyz (Taraxacum kok-saghyz Rodin) cultivation guidelines. St. Petersburg, 2017.

${ }^{1}$ The Ministry of Education Key Laboratory

of Forest Plant Ecology, Northeast Forestry University,

No. 103 Haping road, Xiangfang district, Harbin,

Heilongjiang province, Chaina,

e-mail: shen19772@163.com $\bowtie$;

2Institute of Natural Resources and Ecology,

Heilongjiang Academy of Sciences,

Harbin 150040 ,

e-mail: shen19772@163.com;

ЗФГБНУ ФИЦ Всероссийский институт

генетических ресурсов растений им. Н.И. Вавилова,

190000 Россия, г. Санкт-Петербург, ул. Большая Морская, 42-44,

e-mail: n.konkova@vir.nw.ru $₫$
Поступила в редакцию 27 февраля 2018 года 


\title{
METHODOLOGICAL STUDY ON SELECTION OF CONDITIONS FOR IMPROVING Taraxacum kok-saghyz Rodin SEED GERMINATION
}

\author{
G. Shen 1, 2, F. Chen' ${ }^{2}$ W. Wang', F. Zheng', D. Wei', L. Li' ${ }^{2}$, N.G. Kon 'kova ${ }^{3}$
}

${ }^{1}$ The Ministry of Education Key Laboratory of Forest Plant Ecology, Northeast Forestry University, Harbin 150040, e-mail shen19772@163.com ( $\square$ corresponding author);

${ }^{2}$ Institute of Natural Resources and Ecology, Heilongjiang Academy of Sciences, Harbin, 150040, e-mail shen19772@163.com;

${ }^{3}$ Federal Research Center the Vavilov All-Russian Institute of Plant Genetic Resources, Federal Agency for Scientific Organizations, 42-44, ul. Bol’shaya Morskaya, St. Petersburg, 190000 Russia, e-mail n.konkova@vir.nw.ru ( $\square$ corresponding author)

ORCID:

Shen G. orcid.org/0000-0001-5320-6465

Chen F. orcid.org/0000-0002-8890-9782

Wang W. orcid.org/0000-0003-0465-686X

Zheng F. orcid.org/0000-0002-8966-5230

The authors declare no conflict of interests

Acknowledgments:

The authors wish to thank Mr. Hui Han for his seed test assistance.

The work was performed in the framework of the VIR state assignment on the topic No. 0662-2019-0001.

Supported by the Team Promoting Project of Heilongjiang Academy of Sciences under grant number 2014ST06, and by the Technology Application Research and Development Project of Harbin program under the contract number 2014AE4AE053

Received February 27, 2018

doi: 10.15389/agrobiology.2019.3.548eng

Abstract

Currently, Kok Sagyz is considered to be the most promising source of natural rubber. In many countries significant investments in the development of rubber production technologies based on the use of this plant are being made. Ensuring a high percentage of rapid and uniform germination is important for Kok Sagyz cultivation. In this research we have obtained results significantly extending the idea of temperature as a factor affecting the characteristics of Kok Sagyz seeds germination, which is important for this rubber plant reproduction practice. The aim of our study was to determine a practical and simple method to improve the germination of Taraxacum kok-saghyz seed. An orthogonal array design $\mathrm{L}_{9}\left(3^{4}\right)$ ] was used to optimize three factors: concentration of $\mathrm{KMnO}_{4}$ solution $(0.07 \%, 0.1 \%$, and $0.2 \%)$, soaking time $(1,2$, and $4 \mathrm{~h})$, and germination temperature $\left(4 / 17,17\right.$, and $\left.23{ }^{\circ} \mathrm{C}\right)$. Germination parameters, including germination percentage, $\mathrm{T}_{50}$ (time taken for $50 \%$ of seeds to germinate), germination index, and vigor index, were evaluated. Using analysis of variance, the optimum conditions for germination were determined, i.e. $2 \mathrm{~h}$ of soaking time in $0.07 \% \mathrm{KMnO}_{4}$ solution and a germination temperature of $23{ }^{\circ} \mathrm{C}$. The optimum conditions were subsequently validated. Under the optimized conditions, we achieved a germination percentage of $71 \%, \mathrm{a} \mathrm{T}_{50}$ value of 11 days, and germination and vigor indices of 7.22 and 14.40, respectively. Moreover, we found that in addition to moisture, temperature was the main factor influencing the germination of T. kok-saghyz seeds. Solution composition and concentration and soaking time had little or no effect on germination.

Keywords: germination percentage, germination uniformity, $\mathrm{KMnO}_{4}$, potassium permanganate, Taraxacum kok-saghyz Rodin, Russian dandelion.

\section{Научные собрания \\ IV МЕЖДУНАРОДНАЯ НАУЧНАЯ КОНФЕРЕНЦИЯ \\ «СОВРЕМЕННОЕ СОСТОЯНИЕ, ПРОБЛЕМЫ И ПЕРСПЕКТИВЫ РАЗВИТИЯ АГРАРНОЙ НАУКИ»}

И V МЕЖДУНАРОДНАЯ МОЛОДЕЖНАЯ ШКОЛА-КОНФЕРЕНЦИЯ «РОЛЬ МАКРО- И МИКРОЭЛЕМЕНТОВ В СОВРЕМЕННОМ ЗЕМЛЕДЕЛИИ»

(9-13 сентября 2019 года, ФГБУН НИИСХ Крыма, г. Симферополь)

Направления работы конференции:

- Сельскохозяйственная микробиология

- Биотехнология и физиология растений

- Животноводство и ветеринарная медицина

- Растениеводство и земледелие

- Селекция и семеноводство

- Сельскохозяйственное оборудование

- Мелиорация и управление водными ресурсами

- Информационные технологии в агропромышленном комплексе

Контакты и информация: http://conf.niishk.ru/

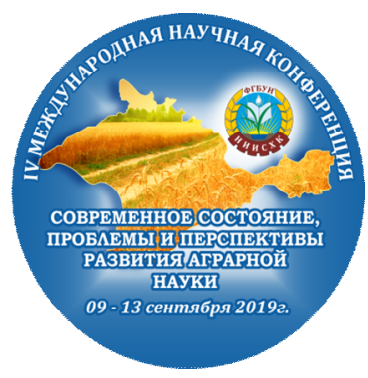

